\title{
What's The Point?
}

They have no extent in time or space, yet mark place and moment well. They stand between the dollars and cents come time to buy or sell. They run beneath the hoods of cars and contact British mains. They terminate our pencil leads and populate our brains (as elements of a debate or purpose in discourse). They measure grades of excellence in every college course. They jut from shorelines into seas and score tests and games of sport. They are even stretched beyond belief when stuck for good retort. * From north around to north again, thirty-two do lie, and these of light on dark clear nights, twinkle in the sky. By them our stocks will rise and fall, one hundred make a carat. They are the aspects, good and bad, that speak to our net merit. They have become synonymous with data from a test, because they

* See figure.
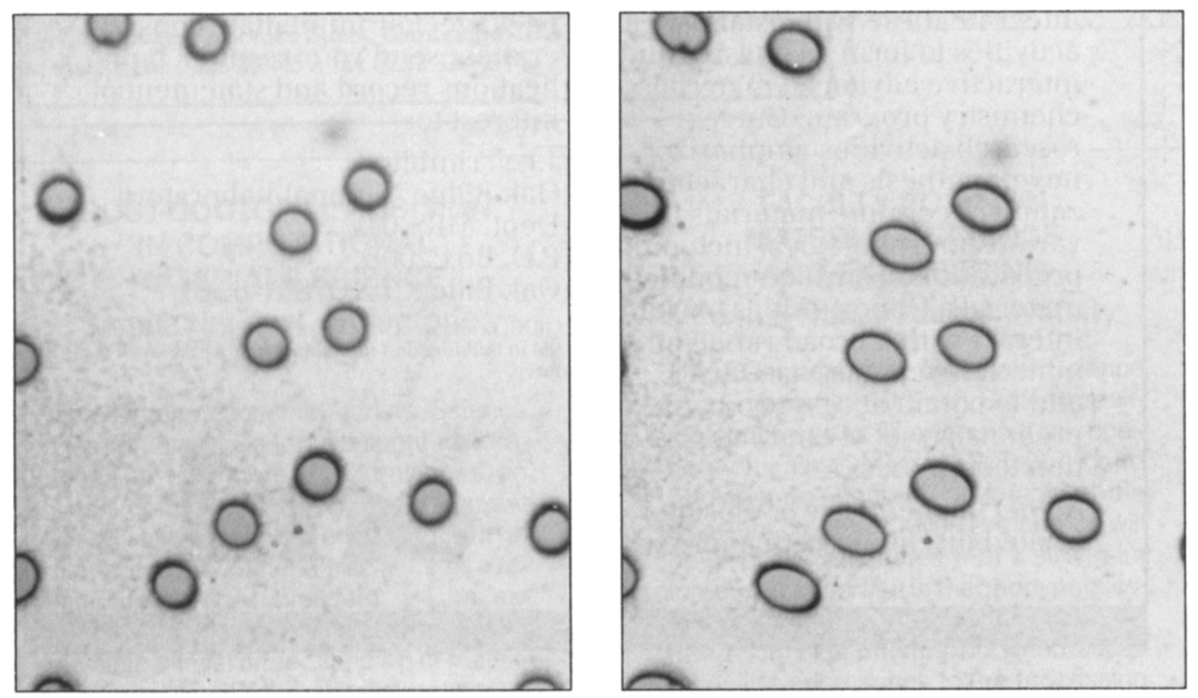

To Stretch a Point: Ever since I was assaulted with the old rubber graph-paper bromide by a colleague and friend (L.C. Feldman of Bell Labs) circa 1970, I have been waiting for the chance to weave it gracefully into something. I was spurred on in 1987 when Robert L. Fleischer (then at $G E$, Schenectady) sent the Bulletin a reprint of a paper he had published in 1972 (with J. Viertl and P. Price, Rev. Sci. Instr. 43 (1972) p. 1708), along with micrographs which at long last experimentally demonstrated the phenomenon. By irradiating a thin rubbery copolymer sheet (65\% dimethyl siloxane, $35 \%$ polycarbonate) with fission fragments and etching the resulting damage tracks, they achieved an array of 14-micron circular holes. Points by any macroscopic standard. Uniaxial stress applied to the sheet makes them elliptical, and a long twenty-three-year quest has come to a gratifying end.

then get plotted out to fit with all the rest. Intransitive, they show us exactly where help ferret out the game. Masons will use mortar when doing it to brick, and still they're used to tell us how paper might be thick. If this type were pica, twelve would be its size. Only into these groups do crystals crystallize. They are the places taken by those courageous souls who bravely lead and trail their reconnaissance patrols. And they are the sums in craps sought out by rolls of dice as well as nature's boundaries twixt steam and water and ice. Even as they're limbs of horses cricket in Great Britain, don't you know. So for such work, what better word could Webster then anoint, but the little, infinitesimal, zero-dimensional point.

\section{E.N. Kaufmann}

\section{Posterminaries' Pearls of Wisdom}

\section{Good Advice}

It is better to take no advice than to take bad advice.

\section{Reverse Disclaimer}

The opinions expressed are those of my employer and do not necessarily reflect those of myself or my family or, for that matter, anyone $I$ know.

R vs. $D$ vs. $P$

Discovery increases the known. Invention rearranges it. Science and technology policy ignores it.

\section{A Verisimilitude}

Refried beans, twice-cooked pork, and election-year politics are similar in purpose and effect.

\section{Great Thinkers}

Visions of the ultimate workings of the universe inspire both Steven Hawking and Charles Manson.

\section{Forecasts}

The light at the end of the tunnel is, more often than not, a mirror.

\section{Economics}

The law of supply and demand guarantees that good solutions and expertise are more dear than tough problems and experts.

\section{Mass Action}

A percentage increase in mass transit fare exceeds the consequent percentage decrease in ridership, and revenues rise. The meaning of "mass" thus extrapolates to one very wealthy chauffeur-poor passenger.

\section{Science Education}

"I doubt if there is a Member of the Senate who really understands to any degree what the SSC is about." (Phil Gramm [R-TX] 8/3/92)

\section{Cosmic Consommé}

"We're still in the soup when it comes to finding an ultimate solution for the solar neutrino problem." (Wick Haxton, Science 256, 6/12/92, p. 1512).

\section{Flip Side of Flops}

Whereas a flop is a bad play and a megaflop is a very bad movie, the more flops a computer has the better.

\section{Cop-out Consequence}

Good-nature and good-sense must ever join; To err is human, to forgive, divine. (According to Pope.) To leave that error uncorrected is sinful, to blame the computer means consignment to digital damnation. (According to the rest of us.)

E.N.K 